\title{
Memory performance, but not information processing speed, may be reduced during early pregnancy
}

Citation for published version (APA):

de Groot, R. H. M., Hornstra, G., Roozendaal, N., \& Jolles, J. (2003). Memory performance, but not information processing speed, may be reduced during early pregnancy. Journal of Clinical and Experimental Neuropsychology, 25(4), 482-488. https://doi.org/10.1076/jcen.25.4.482.13871

Document status and date:

Published: 01/01/2003

DOI:

10.1076/jcen.25.4.482.13871

Document Version:

Publisher's PDF, also known as Version of record

\section{Please check the document version of this publication:}

- A submitted manuscript is the version of the article upon submission and before peer-review. There can be important differences between the submitted version and the official published version of record.

People interested in the research are advised to contact the author for the final version of the publication, or visit the DOI to the publisher's website.

- The final author version and the galley proof are versions of the publication after peer review.

- The final published version features the final layout of the paper including the volume, issue and page numbers.

Link to publication

\footnotetext{
General rights rights.

- You may freely distribute the URL identifying the publication in the public portal. please follow below link for the End User Agreement:

www.umlib.nl/taverne-license

Take down policy

If you believe that this document breaches copyright please contact us at:

repository@maastrichtuniversity.nl

providing details and we will investigate your claim.
}

Copyright and moral rights for the publications made accessible in the public portal are retained by the authors and/or other copyright owners and it is a condition of accessing publications that users recognise and abide by the legal requirements associated with these

- Users may download and print one copy of any publication from the public portal for the purpose of private study or research.

- You may not further distribute the material or use it for any profit-making activity or commercial gain

If the publication is distributed under the terms of Article $25 \mathrm{fa}$ of the Dutch Copyright Act, indicated by the "Taverne" license above, 


\title{
Memory Performance, but not Information Processing Speed, may be Reduced During Early Pregnancy
}

\author{
R.H.M. de Groot ${ }^{1,2}$, G. Hornstra ${ }^{2}$, N. Roozendaal ${ }^{3}$, and J. Jolles ${ }^{3}$ \\ ${ }^{1}$ Department of Human Biology, Maastricht University, The Netherlands, ${ }^{2}$ Nutrition and Toxicology Research Institute Maastricht \\ (NUTRIM), Maastricht University, The Netherlands, and ${ }^{3}$ Department of Psychiatry \& Neuropsychology, \\ Division of Cognitive Disorders, Brain \& Behaviour Institute, Maastricht University, The Netherlands
}

\begin{abstract}
Several studies have investigated aspects of cognitive functioning during late pregnancy or in the period around delivery. The present paper describes a controlled study of neurocognitive functioning in an early phase of pregnancy (14 weeks). Seventy-one pregnant women and 57 control subjects matched for age and education were tested with a cognitive test battery. Intentional learning was tested with the Verbal Learning Test, retrieval from semantic memory with the Fluency Test, and speed of information processing with the Concept Shifting Test, the Stroop test, and the Letter Digit Substitution Test. Results show that performance on tests measuring intentional learning and retrieval from semantic memory were lower in the pregnant group during early pregnancy as compared to a closely matched nonpregnant group. In contrast, speed of information processing was not different between the two groups. The differences observed in memory performance were not large and further research is needed to establish their clinical significance. In addition, the results should be interpreted with care, because our study has a cross-sectional design, which has limitations concerning the fact that preexisting performance differences might be possible. Therefore, longitudinal studies are essential to ascertain clear associations between pregnancy and cognitive performance.
\end{abstract}

\section{INTRODUCTION}

Forgetfulness and changed attentional functions have frequently been reported by pregnant women (Condon, 1987). The majority of studies have reported decreased performance on neurocognitive tasks during pregnancy (e.g., Brindle, Brown, Brown, Griffith, \& Turner, 1991; Buckwalter et al., 1999; Eidelman, Hoffmann, \& Kaitz, 1993; Parsons \& Redman, 1991; Poser, Kassirer, \& Peyser, 1986; Sharp, Brindle, Brown, \& Turner, 1993; Silber, Almkvist, Larsson, \& Uvnas-Moberg, 1990), but some have found no effect of pregnancy (e.g., Morris, Toms, Easthope, \& Biddulph, 1998; Schneider, 1989) or even a positive effect on some cognitive functions (Christensen, Poyser, Pollitt, \& Cubis, 1999; for review see Brett et al.; Brett \& Baxendale, 2001). These discrepant findings may be due to differences in the cognitive tasks used, or differences in the stage of pregnancy of the subjects investigated. Thus, there is no consistent answer to the question whether or not cognitive functioning is affected during pregnancy.

Most of the above-mentioned studies investigated only one or some aspects of cognitive functioning, and only two studies investigated whether cognitive functioning is altered in an early stage of pregnancy (Keenan, Yaldoo, Stress, Fuerst, \& Ginsburg, 1998; Sharp et al., 1993). The

Address correspondence to: R.H.M. de Groot, Department of Human Biology, Maastricht University, P.O. Box 616, 6200MD Maastricht, The Netherlands. Tel.: +31 433881507. Fax: + 31 433670976. E-mail: RHM.deGroot@HB.unimaas.nl Accepted for publication: September 23, 2002. 
possibility that early pregnancy is already characterized by cognitive changes is of importance as there is not yet a profound change in psychosocial circumstances around the pregnant woman. Possible changes in cognitive functioning could therefore more directly be ascribed to biological changes in the body brought about by hormones or by a redistribution of nutrients essential for brain functioning (e.g., long chain highly unsaturated essential fatty acids) in favor of the unborn child.

The present study investigated whether cognitive functioning is different during early pregnancy (14 weeks after the last menstrual period) and, if so, whether specific cognitive functions are affected. A controlled design was chosen in which pregnant women were compared to carefully matched controls, and where performance of memory tasks was compared to performance on tests of information processing. The aspects of cognition we measured in this study were focussed on memory and speed of information processing. The reason for this choice was that pregnant women complain about concentration problems and everyday forgetting in particular (Baildam, 1991; Kane, Harman, Keeler, \& Ewing, 1968; Parsons \& Redman, 1991; Welch, 1991). Sensitive tests are needed in order to detect changes in cognition during pregnancy with reliability and validity, because such a study concerns a healthy population, where there is no reason to expect profound changes in cognitive performance. The tests we decided to use, have already shown their effectiveness in earlier research into neurocognitive functioning in healthy subjects and in subjects with only mild cognitive complaints (Engelberts et al., 2002; Houx, 1991; van Boxtel et al., 1998).

\section{MATERIALS AND METHODS}

\section{Subjects}

Pregnant women were recruited by midwives in the region Maastricht, Heerlen, and Sittard, located in the south-eastern part of the Netherlands, and by the Departments of Obstetrics and Gynecology of hospitals in the same area (University Hospital Maastricht, Atrium Medical Center in Heerlen, and Maasland Hospital in Sittard). The selection criteria for study entry were a gestational age less than 14 weeks, and a normal health, that is, not suffering from any metabolic, cardiovascular, renal, psychiatric, or neurological disorders. Exclusion criteria were diastolic blood pressure higher than $90 \mathrm{mmHg}$, multiple pregnancy, consumption of dietary supplements rich in polyunsaturated fatty acids, and not being of Caucasian origin, in order to limit scatter of the measuring results due to large differences in genetic, social, and cultural patterns.

The nonpregnant women in the control group were friends or family members of the pregnant women, or were recruited by advertisements in local newspapers. All in- and exclusion criteria were the same as for the pregnant population with exception of the pregnancyrelated criteria. Their last pregnancy, if any, was at least 32 weeks before study entry and if they had been pregnant before, they were not breastfeeding during the study.

Seventy-one pregnant women and 57 control subjects volunteered to participate in this study. Groups were matched for age and education (measured on an 8point scale, ranging from primary education to higher vocational training and university; Bie, 1987). All tests were administered in the subject's home, in a situation, which enables testing under favorable conditions.

The study was approved by the Medical Ethics Committee of the University Hospital Maastricht and written consent was obtained from each participant.

\section{Tests for Cognitive Functioning}

\section{Visual Verbal Word Learning Task (WLT)}

To assess learning capacity as well as recall and retrieval from long-term memory, a visual verbal word learning task (Brand \& Jolles, 1985) was completed by the subjects, according to the protocol of the MAAS study (Jolles, Houx, van Boxtel, \& Ponds, 1995). This test is an improved version of a test originally devised by Rey (Rey, 1964). Fifteen words were presented one after the other at 2-s intervals. After presentation, the participants were asked to recall as many words as possible in any order. This procedure was repeated three times. After $20 \mathrm{~min}$ (within this time the tasks mentioned below were performed), delayed recall was measured. Dependent variables were the mean recall over three trials (WLTtot) and the delayed recall (WLTdr) after $20 \mathrm{~min}$. Four different test versions were used across the population to prevent exchange of the words, used in the test between family and friends in our test population. The test versions used in the Words Learning Test were parallel test versions. The words in the lists consisted of frequently used meaningful monosyllabic nouns matched for word frequency. All versions contained the same amount of living versus nonliving words, the words were emotionally neutral and had on average the same amount of letters. 


\section{Concept Shifting Test (CST)}

The Concept Shifting Test (CST) was used to measure visual conceptual and visuomotor tracking (Houx, 1991; Vink \& Jolles, 1985). This test consists of four test sheets. On each test sheet, 16 small circles are grouped in a larger circle. On the first sheet, numbers appear in a fixed random order, on the second sheet letters, and on the third sheet both. Subjects were requested to cross out the items in the right order (1-23-4 (Subtask I), A-B-C-D (Subtask II), 1A-2B-3C (Subtask III), respectively); the time required to do this was measured with a stopwatch. A fourth sheet with empty circles (Subtask IV), which had to be crossed out as fast as possible, was used to correct for motor speed. Mean speed for Subtasks I and II, corrected for motor speed (Subtask IV), was used as a measure of general information processing speed. Subtask III, also corrected for motor speed, was used as a measure of concept shifting ability.

\section{Fluency (FLU)}

The subjects completed a fluency task (Lezak, 1995) as a measure of retrieval from long-term semantic memory. Subjects had to name as many animals as possible within $1 \mathrm{~min}$. Fluency is a measure of the adequate, strategy-driven retrieval of information from semantic memory. The number of animals named was used as dependent variable.

\section{Stroop Color-Word Interference Test}

The Stroop Color-Word Interference Test was used to test selective attention (Klein, Ponds, Houx, \& Jolles, 1997; Stroop, 1935). The test involves three cards displaying 40 stimuli each: color names printed in black (Subtask I), colored patches (Subtask II), and color names printed in one of the other colors (Subtask III). For Subtask I subjects had to read aloud the printed items, for Subtask II they had to name to color of the patches and for Subtask III they had to name the ink color the words were printed in. The amount of extra time needed to discard irrelevant but very salient information (reading) in favor of a less obvious aspect (color naming) was recorded. Mean speed for Subtasks I and II was used as a measure of general information processing speed. Subtask III was used as a measure of color word interference susceptibility.

\section{Letter-Digit-Substitution-Test (LDST)}

The Letter-Digit-Substitution-Test (LDST) is related to the Symbol-Digit Modalities Test developed by Smith (Smith, 1968), which originates from the Digit Symbol Test developed by Wechsler (Wechsler, 1958). The LDST was used to measure the efficiency of operations in working memory. At the top of the test sheet, a box is presented with nine numbers coupled with nine letters in a random order. On the rest of the page, boxes are presented with just letters. Subjects were asked to fill in as many corresponding numbers as possible within $1 \mathrm{~min}$. The total number of digits correctly related to a letter was used as the dependent variable.

\section{Statistics}

One pregnant subject did not have reliable test results, because the conditions under which she performed the cognitive tests were unacceptable. Data for this person were excluded from the analyses. Individual data were screened for extreme values based on normative data from the Maastricht Aging Study (van Boxtel et al., 1998); Five datapoints were considered outliers, with values outside the range of $+/-3 * S D$, and were excluded from the analyses.

Subject characteristics were examined for statistical differences between the two groups by unpaired $t$ tests. The Mann-Whitney $U$-test analyzed the differences in education and number of pregnancies. The group differences for the dependent variables were analyzed by ANOVA with education and total number of pregnancies as covariates. In the analysis of the WLT a correction for test version was applied too. The CST was also analyzed by a two-way ANOVA for group $\times$ repeated measures (two variables), to find out whether there was a differential effect for concept shifting (CST III) or general speed (mean CST I/II). The same was done for the Stroop test. A $p$ level of $<.05$ was considered statistically significant.

\section{RESULTS}

\section{Subject Characteristics}

Table 1 shows the subject characteristics. With an unpaired $t$ test no statistically significant differences were found between the two groups for age, height, and weight. The control subjects tended to have attained a higher level of education $(p=0.0628)$. We therefore decided to use a statistical design in which education was controlled for. The average total number of pregnancies was statistically different between the two groups $(p=.0014)$. Therefore, we corrected for both education and total number of pregnancies.

\section{Intentional Learning Task and Retrieval from Semantic Memory}

The control group had a significantly higher score on the WLTtot (mean $\pm S D$ 11.77 $\pm 1.34, n=57$ ) than the pregnant group $(11.07 \pm 1.35, n=70$, 
Table 1. Subject Characteristics (Mean $\pm S D)$.

\begin{tabular}{|c|c|c|}
\hline Characteristics & $\begin{array}{l}\text { Pregnant group } \\
\quad(n=71)\end{array}$ & $\begin{array}{l}\text { Control group } \\
\quad(n=57)\end{array}$ \\
\hline Age (year) ${ }^{1}$ & $29.5 \pm 3.7$ & $30.5 \pm 4.2$ \\
\hline Education $^{2}$ & $3.9 \pm 1.5$ & $4.4 \pm 1.2$ \\
\hline Height $(\mathrm{cm})$ & $168 \pm 5$ & $168 \pm 6$ \\
\hline Weight (kg) & $70.15 \pm 14.86$ & $70.27 \pm 13.94$ \\
\hline Number of pregnancies* & $n(\%)$ & $n(\%)$ \\
\hline 0 & $0(0)$ & $17(29.8)$ \\
\hline 1 & $25(35.2)$ & $11(19.3)$ \\
\hline 2 & $31(43.7)$ & $17(29.8)$ \\
\hline 3 & $9(12.7)$ & $8(14.0)$ \\
\hline$>3$ & $6(8.4)$ & $4(7.1)$ \\
\hline
\end{tabular}

Table 2. Cognitive Test Performance in the Pregnant Group Versus the Control Group (Mean $\pm S D$ ).

\begin{tabular}{lccc}
\hline Tests & $\begin{array}{c}\text { Pregnant group } \\
n=71\end{array}$ & $\begin{array}{c}\text { Control group } \\
n=57\end{array}$ & $p$ \\
\hline WLTtot (\# words recalled) & $11.07 \pm 1.35$ & $11.77 \pm 1.34$ & $.015^{*}$ \\
WLTdr (\# words recalled) & $11.69 \pm 2.06$ & $12.75 \pm 1.83$ & $.006^{*}$ \\
Fluency (\# words/min) & $24.80 \pm 5.46$ & $27.84 \pm 5.79$ & $.006^{*}$ \\
CST (I+II)/2 (s) & $12.89 \pm 3.13$ & $12.24 \pm 3.13$ & .421 \\
CST (III) (s) & $20.68 \pm 6.21$ & $18.88 \pm 5.42$ & .303 \\
Stroop (I+ II)/2 (s) & $17.09 \pm 2.64$ & $16.52 \pm 2.29$ & .872 \\
Stroop (III) (s) & $33.10 \pm 5.44$ & $31.67 \pm 7.05$ & .491 \\
LDST (\# numbers filled in/min) & $40.69 \pm 6.31$ & $42.32 \pm 6.59$ & .624 \\
\hline
\end{tabular}

Note. Differences between the pregnant group and the control group were corrected for education levels and total number of pregnancies. WLT was also corrected for test version. WLT $=$ Words Learning Test, tot $=$ total (mean of trial I, II and III) $d r=$ delayed recall, CST=Concept Shifting Test, LDST=Letter Digit Substitution Test.

*Significant.

$p=.015)$. The same was found for WLT delayed recall task: $12.75 \pm 1.83$ for the control group $(n=57)$ versus $11.69 \pm 2.06$ for the pregnant group $(n=70, p=.006)$ (see Table 2).

With respect to retrieval from long-term semantic memory, the pregnant group had a significantly lower score for the fluency test than did the control group $(24.80 \pm 5.46, n=70$ vs. $27.84 \pm 5.79, n=57 ; p=.006$ after correction for education and number of pregnancies).

Analyses without correction for number of pregnancies revealed comparable results (WLTtot $p=.013$, WLTdr $p=.004$, FLU $p=.020$ ).

\section{Speed of Information Processing}

General speed of processing and concept shifting in the concept shifting test were not different between the two groups (see also Table 2). Two scores on this test were analyzed; the mean of Version I and II as the general speed of information processing $(p=.421)$ and the score of Version III as a measure of concept shifting ability $(p=.303)$. By two-way repeated measures ANOVA no differential effect was found for concept shifting.

Likewise, there were no significant group differences in scores on the Stroop test $(p=.872$ 
for the group differences concerning the mean of Stroop Version I and II and $p=.491$ for Version III). Also, two-way ANOVA for repeated measures did not show any statistically significant differences. Finally, scores on the Letter Digit Substitution Test were not statistically different between the pregnant and the control groups $(p=.624)$.

\section{DISCUSSION}

The aim of this study was to investigate whether memory and/or information processing speed is different in early pregnancy as compared to the nonpregnant state and, if so, which specific aspects are different. Our results show a clear difference between women in early pregnancy and their matched controls with regard to performance on the WLTtot, its delayed recall, and the fluency test. These findings suggest that intentional learning and retrieval from semantic memory are compromised. In contrast, speed of information processing under simple and more complex conditions was not different. Thus, memory functions in particular are affected in early pregnancy without consequences for attention and speed tasks. However, the differences in cognitive performance between the two groups, although statistically significant, are not large and may not be clinically important. Nevertheless, there is a possibility that these differences are relevant, since they may cause suboptimum functioning. Therefore, further research is needed to establish the clinical significance of the observed differences. In addition, it should be noted that our study had a cross-sectional design, the results of which can be influenced by selection-bias. This implies that preexisting performance differences could have been present between the groups. Although the careful matching between the groups makes it improbable that there is a systematic difference between the groups, a longitudinal study is needed in order to rule out this possibility. Till then the results of this cross-sectional study should be interpreted with caution.

As far as we know, there are only few studies, which investigated cognition in early pregnancy
(Keenan et al., 1998; Sharp et al., 1993). In our study, explicit memory (as measured by WLTtot and WLTdr) was significantly impaired in the pregnant group compared to the control group. These results are consistent with those of Keenan et al. (1998), who, however, only found statistically significant differences in explicit memory in the third trimester of pregnancy. Their group sizes, however, were small (10 pregnant women and 10 women in the control group). Sharp et al. (1993) detected deficits in explicit memory in all trimesters of pregnancy. Studies performed later in pregnancy have yielded conflicting data. Casey, Huntsdale, Angus, and Janes (1999), as well as McDowall and Moriarty (2000) did not find any effect of pregnancy on different memory functions. Brindle et al. (1991) found that implicit memory was significantly impaired in primigravidae, while explicit memory was unimpaired in contrast to our findings.

In our study, speed of information processing did not differ between the pregnant women and the control women. In contrast, Buckwalter et al. (1999) showed a lower performance on tasks requiring speed of cognitive processing and conceptual tracking during pregnancy as compared with performance after delivery. However, they administered the tasks late in pregnancy (19.8 days prior to delivery), in contrast to our study, and it may be that these cognitive functions are only affected later in pregnancy. Thus, in early pregnancy performance on intentional learning tests may be a more sensitive indicator of changed cognitive functioning than performance on speed tasks. This is especially since women in the earlier phases of pregnancy may still have sufficient attentional 'resources' to cope with the demands of speed tasks.

There is uncertainty about the mechanisms underlying the performance deficits seen in pregnancy. Changes in mood and even depression, as well as biological factors, or a combination of biological and psychosocial factors have been mentioned. Concerning the correlation between mood during pregnancy and cognitive functioning, Harris, Deary, Harris, Lees, and Wilson (1996) observed that, after they corrected for depression pregnancy was no longer associated with cognitive dysfunction. However, 
Keenan et al. (1998) found that although pregnant women scored higher on both depression and anxiety scales, the pregnancy-related decline in memory was not attributable to these factors. It is not likely that our findings were influenced by mood changes or depression, because our study was performed in early pregnancy, when mood changes are minor, if present, in contrast to late pregnancy, close to delivery, when a substantial proportion of pregnant women experience sometimes profound psychological changes. However, preexisting mood differences between our two groups cannot be completely ruled out, as this is one of the limitations of a cross-sectional study design as has been stated before.

Several biological factors may underlie the cognitive decline during pregnancy. One factor may be hormonal, because the levels of estrogen, progesterone, testosterone, and dehydroepiandosterone change considerably during pregnancy. Buckwalter et al. (1999) tried to find a relation between impaired memory and the above-mentioned hormones. They confirmed that cognitive functioning decreased during pregnancy, especially aspects of verbal memory, and that negative mood states were reported more often during pregnancy than after delivery. However, no consistent correlation was found between impaired memory and negative mood state or steroid hormone concentrations. Oxytocin has been mentioned as a possible factor, influencing cognitive function, but a correlation between oxytocin concentration and cognitive function during pregnancy has not been found (Silber et al., 1990). Moreover, because the oxytocin concentration does not change in early pregnancy, this factor cannot explain the compromised intentional learning and retrieval from semantic memory found in our study.

Another biological factor, which may be causally implicated in the cognitive changes during pregnancy, is nutrition. This particular applies to longer-chain, highly-unsaturated derivatives of essential fatty acids, the so-called LC-PUFA. The latter compounds are very important structural components in brain tissue, where they perform an array of membrane-associated functions (Sastry, 1985). For instance, they can influence membrane fluidity and thus affect the activities of neurotransmitters, peptides, releasing factors, and hormones. A change in LC-PUFA availability could, therefore, explain our findings. During pregnancy, accretion of maternal, placental and fetal tissue occurs and, consequently, the LC-PUFA requirements of pregnant women and their developing fetuses are high (Clandinin et al., 1980). To obtain these LC-PUFA, the fetus mainly depends on placental transfer and thus on the EFA status and/or supply of the mother (Innis, 1991). The overall biochemical LC-PUFA status of women declines during pregnancy (Al, van Houwelingen, \& Hornstra, 2000) which may have functional consequences on maternal cognition.

In summary this cross-sectional study demonstrated less adequate memory performance in an early pregnancy group as compared to a matched group of nonpregnant women. A longitudinal study will be needed to establish clear association with pregnancy, especially any causal relation, and to find out whether the observed differences in early pregnancy disappear at some point after delivery. Currently, such a study is in progress in our laboratory and results will become available later this year.

\section{REFERENCES}

Al, M.D., van Houwelingen, A.C., \& Hornstra, G. (2000). Long-chain polyunsaturated fatty acids, pregnancy, and pregnancy outcome. The American Journal of Clinical Nutrition, 71, 285S-291S.

Baildam, E. (1991). Doctor as mum. BMJ, 303, 424.

Bie, S.E.D. (1987). Standaardvragen 1987: Voorstellen voor uniformering van vraagstellingen naar achtergrondkenmerken en interviews [Standard questions 1987: Proposal for uniformisation of questions regarding background variables and interviews] (2nd ed.). Leiden, The Netherlands: Leiden University Press.

Brand, N., \& Jolles, J. (1985). Learning and retrieval rate of words presented auditorily and visually. The Journal of General Psychology, 112, 201-210.

Brett, M., \& Baxendale, S. (2001). Motherhood and memory: A review. Psychoneuroendocrinology, 26, 339-362.

Brindle, P.M., Brown, M.W., Brown, J., Griffith, H.B., \& Turner, G.M. (1991). Objective and subjective memory impairment in pregnancy. Psychological Medicine, 21, 647-653.

Buckwalter, J.G., Stanczyk, F.Z., McCleary, C.A., Bluestein, B.W., Buckwalter, D.K., Rankin, K.P., 
Chang, L., \& Goodwin, T.M. (1999). Pregnancy, the postpartum, and steroid hormones: Effects on cognition and mood [published erratum appears in Psychoneuroendocrinology 1999 July; 24, 581]. Psychoneuroendocrinology, 24, 69-84.

Casey, P., Huntsdale, C., Angus, G., \& Janes, C. (1999). Memory in pregnancy. II: Implicit, incidental, explicit, semantic, short-term, working and prospective memory in primigravid, multigravid and postpartum women. Journal of Psychosomatic Obstetrics and Gynaecology, 20, 158-164.

Christensen, H., Poyser, C., Pollitt, P., \& Cubis, J. (1999). Pregnancy may confer a selective cognitive advantage. Journal of Reproductive and Infant Psychology, 17, 7-25.

Clandinin, M.T., Chappell, J.E., Leong, S., Heim, T., Swyer, P.R., \& Chance, G.W. (1980). Intrauterine fatty acid accretion rates in human brain: Implications for fatty acid requirements. Early Human Development, 4, 121-129.

Condon, J.T. (1987). Altered cognitive functioning in pregnant women: A shift towards primary process thinking. The British Journal of Medical Psychology, 60, 329-334.

Eidelman, A.I., Hoffmann, N.W., \& Kaitz, M. (1993). Cognitive deficits in women after childbirth. Obstetrics and Gynecology, 81, 764-767.

Engelberts, N.H., Klein, M., van der Ploeg, H.M., Heimans, J.J., Ader, H.J., van Boxtel, M.P., Jolles, J., \& Kasteleijn-Nolst Trenite, D.G. (2002). Cognition and health-related quality of life in a welldefined subgroup of patients with partial epilepsy. Journal of Neurology, 249, 294-299.

Harris, N.D., Deary, I.J., Harris, M.B., Lees, M.M., \& Wilson, J.A. (1996). Peripartal cognitive impairment: Secondary to depression? The British Journal of Health Psychology, 1, 127-136.

Houx, P. (1991). Cognitive aging and health-related factors. Limburg, Maastricht: Rijksuniversiteit

Innis, S.M. (1991). Essential fatty acids in growth and development. Progress in Lipid Research, 30, 39-103.

Jolles, J., Houx, P., Boxtel van, M., \& Ponds, R. (1995). Maastricht aging study: Determinants of cognitive aging. Maastricht: Neuropsych Publishers.

Kane, F.J., Jr., Harman, W.J., Jr., Keeler, M.H., \& Ewing, J.A. (1968). Emotional and cognitive disturbance in the early puerperium. The British Journal of Psychiatry, 114, 99-102.

Keenan, P.A., Yaldoo, D.T., Stress, M.E., Fuerst, D.R., \& Ginsburg, K.A. (1998). Explicit memory in pregnant women. American Journal of Obstetrics and Gynecology, 179, 731-737.

Klein, M., Ponds, R.W., Houx, P.J., \& Jolles, J. (1997). Effect of test duration on age-related differences in Stroop interference. Journal of Clinical and Experimental Neuropsychology, 19, 77-82.
Lezak, M.D. (1995). Neuropsychological assessment (3rd ed.). New York: Oxford University Press.

McDowall, J., \& Moriarty, R. (2000). Implicit and explicit memory in pregnant women: An analysis of data-driven and conceptually driven processes. The Quarterly Journal of Experimental Psychology, 53, 729-740.

Morris, N., Toms, M., Easthope, Y., \& Biddulph, J. (1998). Mood and cognition in pregnant workers [see comments]. Applied Ergonomics, 29, 377-381.

Parsons, C., \& Redman, S. (1991). Self-reported cognitive change during pregnancy. Australian Journal of Advanced Nursing, 9, 20-29.

Poser, C.M., Kassirer, M.R., \& Peyser, J.M. (1986). Benign encephalopathy of pregnancy. Preliminary clinical observations. Acta Neurologica Scandinavica, 73, 39-43.

Rey, A. (1964). L'examen psychologique dans les cas d'encephalopathie traumatique [Psychological assessment in cases of traumatic brain injury]. Paris: Presses Universitaires de France.

Sastry, P.S. (1985). Lipids of nervous tissue: Composition and metabolism. Progress in Lipid Research, 24, 69-176.

Schneider, Z. (1989). Cognitive performance in pregnancy. Australian Journal of Advanced Nursing, 6, 40-47.

Sharp, K., Brindle, P.M., Brown, M.W., \& Turner, G.M. (1993). Memory loss during pregnancy [see comments]. British Journal of Obstetrics and Gynaecology, 100, 209-215.

Silber, M., Almkvist, O., Larsson, B., \& UvnasMoberg, K. (1990). Temporary peripartal impairment in memory and attention and its possible relation to oxytocin concentration. Life Sciences, $47,57-65$.

Smith, A. (1968). The Symbol Digit Modalities Test: A neuropsychologic test for economic screening of learning and other cerebral disorders. Learning Disorders, 3, 83-91.

Stroop, J. (1935). Studies of interference in serial verbal reaction. Journal of Experimental Psychology, 18, 643-662.

van Boxtel, M.P., Buntinx, F., Houx, P.J., Metsemakers, J.F., Knottnerus, A., \& Jolles, J. (1998). The relation between morbidity and cognitive performance in a normal aging population. The Journals of Gerontology. Series A, Biological Sciences and Social Sciences, 53, M147-M154.

Vink, M., \& Jolles, J. (1985). A new version of the Trail Making Test as an information processing task. Journal of Clinical Neuropsychology, 7, 162.

Wechsler, D. (1958). The measurement and appraisal of adult intelligence. Baltimore: Williams \& Wilkins.

Welch, J. (1991). Labouring brains. BMJ, 303, 253. 